\title{
Artesãos, metafísica e ciência: as relações entre história da ciência e filosofia da ciência em Edgar Zilsel, Alexandre Koyré e Paolo Rossi ${ }^{120}$
}

\section{Artisans, metaphysics and science: the rela- tions between history of science and philo- sophy of science in Edgar Zilsel, Alexandre Koyré and Paolo Rossi}

Rodrigo Cristino de Faria

Doutorando pela USP

Resumo: Neste artigo, argumento que, apesar de suas diferenças metodológicas e divisões institucionais, a filosofia da ciência e a história da ciência são disciplinas que podem ser conectadas. Procuro exemplificar isso através da análise das concepções de Revolução Científica de três autores: Edgar Zilsel, Alexandre Koyré e Paolo Rossi. O primeiro argumenta que a Revolução Científica ocorre como efeito de uma mudança social; o segundo, como efeito de uma mudança da metafísica; enquanto o terceiro une, de certa forma, as concepções dos dois autores anteriores. Nos três autores, a interação entre his-

\footnotetext{
${ }_{120}$ O presente trabalho foi realizado com apoio da Coordenação de Aperfeiçoamento de Pessoal de Nível Superior - Brasil (CAPES) - Código de Financiamento 001.
} 
tória e filosofia é constitutiva de uma prática de pesquisa que une as duas abordagens.

Palavras-chave: Filosofia; História da ciência; Ciência

Abstract: In this article, I argue that despite their methodological differences and institutional divisions, philosophy of science and history of science can be connected disciplines. I try to exemplify this through the analysis of the conceptions of the Scientific Revolution of three authors: Edgar Zilsel, Alexandre Koyré and Paolo Rossi. The first argues that the Scientific Revolution occurs as an effect of social change; the second, that it occurs as the effect of a change in metaphysics; while the third unites, to a certain extent, the conceptions of the two previous authors. In all three authors, the interaction between history and philosophy is constitutive of a research practice that unites the two approaches.

Keywords: Philosophy; History of science; Science

A atividade científica pode ser estudada a partir de vários pontos de vista, entre eles o da história da ciência e o da filosofia da ciência. Entretanto, apesar das afinidades percebidas entre as duas disciplinas, alguns autores apontam para as especificidades que as distinguem: o historiador olha para um episódio e se pergunta o que aconteceu, quando e onde (e talvez como se chegou até aquele evento ou estrutura); o filósofo procura saber quais justificações lógicas e/ou racionais são mobilizadas. A relação entre as duas áreas foi descrita pelo filósofo da ciência Ronald Giere (1973) como um "casamento de conveniência"121, devido ao caráter descritivo da história, por um lado, e normativo da filosofia, por outro. O historiador da ciência Kenneth Caneva (2012, p. 51) afirma que "nós historiadores lidamos com particularidades ligadas ao tempo, e nossas verdades estão naquelas particularidades. Em contraste, filósofos buscam verdades atemporais das quais as particularidades históricas foram destiladas" ${ }^{22}$. Prima facie, a união entre

\footnotetext{
121 No original: "marriage of convenience". Tradução minha.

$122 \quad$ No original: "We historians deal with time-bound particulars, and our truths lie in those particulars. In contrast, philosophers seek timeless truths from which the historical particulars have been distilled off". Tradução minha.
} 
história da ciência e filosofia da ciência não iria, então, além de manifestações de boa-vontade frustradas por diferenças metodológicas irreconciliáveis.

Acredito, contudo, que a história da ciência e a filosofia da ciência podem ser praticadas de forma conjunta nos estudos sobre a atividade científica do passado (e do presente). Isso se dá, antes de tudo, porque ambas compartilham o mesmo objeto de estudo: a ciência e suas várias manifestações e influências. Mas, num nível mais profundo, a relação entre as duas disciplinas pode se basear na própria produção de conhecimento em cada uma delas: por um lado, o historiador da ciência adota, ainda que de modo não plenamente articulado ou consciente ${ }^{123}$, alguma concepção filosófica acerca da realidade dos processos históricos, de seus atores e constituintes, do que deve ser considerado como ciência, objetividade, racionalidade, relevância explicativa das hipóteses teóricas, realismo-antirrealismo das teorias etc. Por outro, o filósofo da ciência necessita da história da ciência para que suas análises não sejam puras abstrações lógicas completamente desligadas do desenvolvimento do conhecimento científico, de sua gênese e de seu presente estado. Mesmo um autor com Ernest Nagel, ligado ao Positivismo Lógico, uma escola filosófica tradicionalmente conhecida como indiferente à história da ciência (mas veja-se infra), assume que se deva levá-la em conta. Ao tratar dos aspectos filosóficos da redução teórica, Nagel (1979, p. 363) diz que certas afirmações geram controvérsias desnecessárias por negligenciar certas "considerações elementares"124 sobre a historicidade da ciência e por "se esquecerem que as ciências têm uma história"125. Segundo o Oxford Companion to Philosophy (PAPINE-

$123 \quad$ Kostas Gavroglu (2007, p. 201-202) afirma que, ainda que desejável, a tomada de posição do historiador em relação aos problemas filosóficos da ciência não é um pressuposto de suas atividades; ele deve, contudo, assumir pelo menos uma "posição pragmática".

124 No original: "elementary considerations". Tradução minha.

125 No original (e cito o passo completo): "In any event, arguments for such claims often appear to forget that the sciences have a history, and that the reducibility (or irreducibility) of one science to another is contigent upon the specific theory employed by the latter discipline at some stated time" (NAGEL, 1979, p. 363). Tradução minha. 
AU, 2005, p. 852), a filosofia da ciência é uma subdisciplina da filosofia cujas questões podem ser reunidas em dois grandes grupos: a epistemologia da ciência (que discute a justificação e a objetividade do conhecimento científico) e a metafísica da ciência (que trata dos aspectos da realidade descobertos pela ciência); em ambos, o recurso à história da ciência é importante, seja como fonte de estudos de caso, seja como "laboratório" de teste para as teorias filosóficas. Como bem resume Norwood Russell Hanson (1962, p. 580), parafraseando Immanuel Kant, "a história da ciência sem filosofia da ciência é cega [...] [e] a filosofia da ciência sem história da ciência é vazia"126.

A Revolução Científica que ocorre, grosso modo, entre os séculos XV e XVII é um dos episódios da história da ciência mais estudados, tanto por historiadores quanto por filósofos, o que torna esses estudos um campo fértil para a análise das relações entre história da ciência e filosofia da ciência ${ }^{127}$. O que pretendo fazer neste texto é dar alguns exemplos de pesquisas sobre a ciência desse período visando analisar, ainda que sucintamente, o modo com que procuram unir história da ciência e filosofia da ciência nos seus textos, ao mesmo tempo que apontando diferentes possibilidades racionais de se empreender um estudo histórico-filosófico sobre a atividade científica ${ }^{128}$. Escolhi três autores que, ainda que cheguem a conclusões diversas $126 \quad$ No original: "history of science without philosophy of science is blind. [...] philosophy of science without history of science is empty". Tradução minha.

127 Um levantamento historiográfico da Revolução Científica, com alguns comentários sobre a relação entre história da ciência e filosofia da ciência, pode ser encontrado em Cohen (1994). Um levantamento dos estudos filosóficos centrados na mudança científica, e com alguma ênfase na Revolução Científica, pode ser encontrado em Laudan et al. (1986).

128 O objetivo deste artigo não é nem deduzir um modelo universal de interação entre história e filosofia da ciência, nem tratar exaustivamente das suas relações, seja pela via história $\square$ filosofia, em que as "posições pragmáticas" citadas na nota 4 podem ser as mais diversas e mais ou menos sofisticadas, seja pela via filosofia $\square$ história, em que o recurso à história da ciência por parte de filósofos varia imensamente (ainda que, depois da virada historicista de Thomas Kuhn e outros, não se negue a importância da história para a filosofia da ciência). O objetivo do artigo é apenas mostrar três casos concretos em que a análise histórica da ciência se imbrica com a análise filosófica, e nos quais ambas se influenciam mutuamente. 
sobre a Revolução Científica e tenham pontos de vistas distintos sobre a ciência, dialogam entre si através de suas obras: Edgar Zilsel, que propõe uma explicação histórico-sociológica para o nascimento da ciência moderna e tenta incluir a história da ciência no projeto metodológico do Positivismo Lógico; Alexandre Koyré, que defende uma visão intelectualista da Revolução Científica, entendida sobretudo como uma mudança de concepção metafísica; e Paolo Rossi, pela sua utilização de uma tradição específica da história da ciência (no caso, aquela de Zilsel) para iluminar uma mudança filosófica na concepção de natureza, unindo, de certa forma, a abordagem dos dois autores anteriores. Nesse diálogo, os autores estabelecem uma forma de unir história e filosofia da ciência.

\section{Zilsel: artesãos e Positivismo Lógico}

Edgar Zilsel é conhecido pela tese que leva seu nome ${ }^{129}$, proposta em seus escritos das décadas de 1930 e 1940. De modo genérico, essa tese afirma que a ciência moderna nasce a partir das condições sociológicas geradas pelo capitalismo nascente entre os séculos XIV e XVII, em que o conhecimento prático dos artesãos se une àquele teórico dos humanistas e das pessoas com treinamento formal das universidades (ZILSEL, 2003, p. 1-6). Tal tese, um dos pilares da historiografia da ciência no século XX, nasce dentro de um contexto marxista preocupado com as influências sociais na ciência, mas sem os excessos deterministas de Boris Hessen ${ }^{130}$, e pode ser considerada uma generalização dos estudos de Leonard Olschki sobre a influência da técnica em Galileu ${ }^{131}$.

Entretanto, acredito que essa tese tem sido tomada de forma isolada, fora do projeto global que Zilsel pretendia levar

\footnotetext{
Para uma análise exaustiva das relações, pressuposições e implicações entre as duas disciplinas, ver Mauskopf e Schmaltz (2012), Pécheux e Fichant (1989), e Rossi (1975).

129 Ver, por exemplo, Shapin (1981).

130 Ver Freudenthal e McLaughlin (2009), especialmente p. 1-41.

131 Uma visão geral sobre as obras de Olschki pode ser encontrada em Cohen (1994, p. 322-328).
} 
a cabo: mostrar que a história pode ser estudada com os mesmos métodos das ciências da natureza (especialmente os da física), que pode ser explicada a partir de leis universais, e que predições históricas são - em princípio, ao menos - possíveis (ZILSEL, 2003, p. 200-208; ibid., p. 221-223). Esse projeto está ligado à escola filosófica da qual Zilsel fazia parte: o Positivismo Lógico defendido pelos participantes do Círculo de Viena.

Uma das bandeiras do Círculo de Viena era a ideia da unidade da ciência. Tal ideia contém dois pontos: o primeiro é que as ciências (ao menos aquelas que se arrogam o direito de serem chamadas assim) são - ou deveriam ser - unificadas sob uma mesma metodologia; o segundo, que elas poderiam ser reduzidas, eventualmente, à física (BUNGE, 2011, p. 145). Zilsel acreditava que a ideia da unidade da ciência deveria ser demonstrada empiricamente, e não de forma normativa, tal como os outros integrantes do Círculo propunham.

Essa não era a única divergência de Zilsel com os seus colegas do Círculo de Viena. Zilsel acreditava que também a história e a sociologia, e não apenas as ciências da natureza, poderiam ser compreendidas na unidade da ciência. Ainda que outros autores participantes do Círculo, como Otto Neurath e Philipp Frank, apresentassem preocupações com a história e a sociologia ${ }^{132}$, tais preocupações apareciam aos olhos de Zilsel como insuficientes. Um exemplo dessa atitude está no comentário que Zilsel faz acerca de um livro de sociologia de Neurath: para ele, "o livro não tem nenhum interesse no conteúdo vivo da sociologia; em todo caso, muito menos do que na promoção das ideias lógicas básicas da escola de filosofia de Viena"133 (ZILSEL, 2003, p. xlv). Para Zilsel, eram necessárias tanto uma fundamentação da aplicação da metodologia das ciências naturais na história e na sociologia, quanto uma prática efetiva de pesquisas históricas e sociológicas com esse novo método.

132 Sobre essas preocupações, e uma reavaliação do suposto desprezo em relação às ciências humanas que tradicionalmente é creditado ao Positivismo Lógico, ver Nemeth (2007).

$133 \quad$ No original: "The book has no intrinsic interest in the living content of sociology - in any case, a lot less than in the promotion of the basic logical ideas of the Vienna school of philosophy". Tradução minha. 
É dentro dessa perspectiva que a obra de Zilsel pode ser mais bem compreendida. Sua tese de doutorado tratou do problema da aplicação da lei estatística dos grandes números na natureza: sua pergunta era sobre como era possível, afinal, que o resultado matemático e a natureza coincidissem. Pouco depois, passou a tratar da possibilidade da aplicação de leis gerais na história. Sua habilitationsschrift (uma espécie de tese de pós-doutorado necessária para a obtenção da venia legendi, a permissão para ensinar em nível universitário na Áustria) tratava do surgimento do conceito de gênio no Renascimento. Nela, Zilsel faz uma pesquisa histórica exaustiva e ao final lança teses em forma de leis gerais (ZILSEL, 2003, p. xxxviii-xliv).

Os trabalhos que Zilsel publica nos Estados Unidos entre 1939 e 1944, ano em que comete suicídio, voltam-se para a questão do surgimento da ciência moderna na Europa e para a aplicação dos métodos da física na história. A metodologia historiográfica de Zilsel parte do princípio de que "como experimentos não são possíveis em história, o único modo de encontrar leis históricas é através da comparação entre vários países e culturas"134 (ZILSEL, 2003, p. 205-206). Notando, porém, que a ciência surge apenas em uma civilização, a da Europa dos séculos XVI e XVII, Zilsel se propõe a procurar as condições sociológicas que acompanham a emergência da ciência na Europa e que estão ausentes em outras culturas. Dois fatores são de especial importância na explicação de Zilsel: (i) a emergência do capitalismo e as novas necessidades tecnológicas, bem como as mudanças sociais por ele geradas, e (ii) a consequente nova valoração social dos artesãos e engenheiros, cujos métodos experimentais foram adotados pelos intelectuais das universidades e humanistas:

A ascensão social do método experimental da classe dos trabalhadores manuais para as fileiras dos intelectuais das universidades no início do século XVII foi um evento decisivo na história da ciência. A ciência natural necessita de teoria e matemática assim como de experimentos e observações. Apenas homens treinados teoricamente

\footnotetext{
$134 \quad$ No original: "Since experiments are not feasible in history, comparison of various countries and cultures is the only way of finding historical laws". Tradução minha.
} 
com intelectos treinados racionalmente eram capazes de fornecer a outra metade do método para a ciência ${ }^{135}$ (ZILSEL, 2003, p. 93).

O que ocasiona a nova valoração social dos artesãos e engenheiros, bem como a adoção de seus métodos e de seu ideal de progresso pelos intelectuais das universidades, capazes de sistematizar o conhecimento empírico em leis e teorias, são as demandas geradas pelo capitalismo nascente. De posse do método experimental dos artesãos e do conhecimento matemático dos humanistas e intelectuais universitários, o novo cientista ${ }^{136}$ produz a ciência moderna.

Zilsel pretendia apresentar sua concepção da gênese da ciência moderna como uma lei histórica: a ciência só pode surgir em condições sociais e econômicas específicas, em que haja grupos de artesãos capazes de ascender socialmente ao nível das pessoas com educação formal (ZILSEL, 2003, p. 231-232), e assim ligar conhecimentos práticos e teóricos. Dessa forma, poderia explicar, por exemplo, porque a ciência não surgiu na Antiguidade: para ele, "a ciência não pode se desenvolver numa civilização baseada em trabalho escravo" 137 (ibid., p. 18).

A concepção de ciência de Zilsel é, talvez, muito estreita (COHEN, 1994, p. 340). Para ele, a ciência é a união de teorias matemáticas e experimentação, de regularidades observacionais subsumidas em leis matemáticas. Zilsel enfatiza o lado experi-

No original: "The social rise of the experimental method from the class of manual laborers to the ranks of university-scholars in the early seventeenth century was a decisive event in the history of science. Natural science needs theory and mathematics as well as experiments and observations. Only theoretically educated men with rationally trained intellects were able to supply that other half of its method to science". Tradução minha.

136 O próprio Zilsel utiliza o termo "cientista" [scientist], e não "filósofo natural" [natural philosopher] para se referir ao novo praticante da ciência nascida nas condições por ele apresentadas. O "filósofo natural" parece ser considerado como um membro do conjunto dos "intelectuais" [scholars] que não possuíam e desdenhavam o método experimental dos artesãos: "O método experimental não descendeu, e nem poderia, das ideias metafísicas dos filósofos naturais" [No original: "The experimental method did not and could not have descended from the metaphysical ideas of the natural philosophers". Tradução minha.] (ZILSEL 2003, p. 79).

$137 \quad$ No original: "science cannot develop in a civilization based on slave labor". Tradução minha. 
mental da ciência moderna, e seu relato da Revolução Científica procura explicar justamente como o chamado método experimental desenvolvido originalmente pelos artesãos foi apropriado por estudiosos, como Galileu e Gilbert, capazes de utilizá-lo para a criação de teorias científicas. Nesse sentido, as posições de Zilsel sobre a natureza da ciência são as mesmas do Positivismo Lógico, em que teorias científicas são estruturas lógico-matemáticas contendo leis confirmáveis através da experiência sensível.

A tentativa de mostrar que a história pode conter leis gerais, como aquela sobre a emergência da ciência moderna, tem como fim a inserção da história no rol das verdadeiras ciências, de acordo com o projeto de unidade da ciência do Círculo de Viena. A grande diferença de Zilsel para os outros positivistas lógicos está na sua convicção de que a unidade da ciência não deve ser um programa baseado apenas em análise lógico-linguística, mas numa pesquisa empírica (KROHN; RAVEN, 2000, p. 929). A obra de Zilsel se divide em duas áreas que se reforçam mutuamente: uma investigação sobre a aplicação de leis na natureza e na história, e - naquilo que pode ser considerado um estudo de caso dessa investigação - um estudo sobre o surgimento da ciência moderna, procurando as leis que determinaram o surgimento da ciência na Europa do século XVII e não em qualquer outro lugar ou época. Assim, Zilsel apresenta uma filosofia da história baseada nos princípios do Positivismo Lógico e um estudo de caso acerca do surgimento da ciência moderna, em que a pesquisa histórica procura dar conteúdo à filosofia, e esta muda o método daquela, formando, as duas, um todo indissolúvel na prática ${ }^{138}$.

As ideias de Zilsel, especialmente a sua tese do artesão -intelectual, não foram aceitas unanimemente pela comunidade dos historiadores da ciência. Uma das visões discordantes vem da obra de Alexandre Koyré, que propõe outro modo de entender a Revolução Científica, baseado numa concepção filosófica diferente daquela de Zilsel.

$138 \quad$ Uma das possíveis razões para o fracasso de Zilsel em obter a venia legendi está em seu modo de entender como a filosofia deve ser feita: para ele, a filosofia deve ser estudada sempre de modo conjugado com a história e as ciências. Sobre isso ver Krohn e Raven (2000, p. 927-928). 


\section{Koyré: metafísica e matemática}

Já se disse que Alexandre Koyré é o pai da atual historiografia da ciência (BELTRÁN, 1995, p. 11). A ele se deve o estabelecimento da ideia de que houve uma Revolução Científica no século XVII - ainda que não tenha sido o criador do conceito $^{139}$, suas obras, especialmente seus Études Galiléennes, de 1939-1940, ajudaram a delinear os traços gerais das mudanças que marcam a nova ciência, transformando a ideia numa ferramenta analítica importante para os historiadores da ciência. Koyré se volta principalmente contra a ideia positivista de que a ciência se constrói através do aporte indutivo de fatos que permitem a criação de teorias cada vez mais abrangentes, e procura mostrar o papel preponderante da metafísica na história da ciência (AGASSI, 2008, p. 119).

A ideia básica de Koyré é que a Revolução Científica é "uma verdadeira mutação do intelecto humano"140 (KOYRÉ, 1966, p. 11). Essa afirmação já mostra a diferença de foco de Koyré em relação a autores como Zilsel, em que os componentes sociais têm papel ativo na gênese da nova ciência. A "mutação" de que fala Koyré se resolve em dois pontos principais: a destruição e a geometrização do cosmos, ou seja, a substituição do mundo finito e hierarquizado por outro infinito e unificado em suas leis e componentes básicos, além da substituição do espaço aristotélico, baseado na existência de lugares naturais para os elementos, pelo espaço euclidiano, extensão infinita e homogênea (KOYRÉ, 1957, p. viii).

Para Koyré, é com Galileu - e até certo ponto, com Descartes, apesar de sua "geometrização em exagero"141 da natureza (KOYRÉ, 1966, p. 131) - que a retomada de uma metafísica pitagórico-platônica possibilita a matematização da natureza. Mas se, em Platão, o mundo físico é sempre uma cópia imperfeita da ideia, e por isso impróprio para a obtenção de conheci-

139 Sobre o desenvolvimento do conceito de Revolução Científica, ver Lindberg (1990, p. 1-26).

$140 \quad$ No original: "une véritable mutation de l'intellect humain". Tradução minha.

141 No original: "géométrisation à outrance". Tradução minha. 
mento certo por causa das vicissitudes da matéria, com Galileu essa distinção entre matéria e ideia se apaga: "a forma geométrica é homogênea à matéria: eis porque as leis geométricas possuem valor real, e dominam a física"142 (ibid., p. 283). Em um mundo matematizado, escrito em caracteres geométricos, o cientista pode estabelecer leis numéricas e criar teorias científicas que gozam da exatidão das matemáticas - ao contrário da física qualitativa baseada na metafísica aristotélica.

Os focos dessa mutação intelectual são a astronomia e a física - principalmente a mecânica: "todo desentendimento entre a física antiga e a moderna pode ser reduzido a isto: enquanto, para Aristóteles, o movimento é necessariamente uma ação, ou mais precisamente uma atualização, [...] ele se tornou, para Galileu e Descartes, um estado"143 (KOYRÉ apud GILLISPIE, 1981, p. 485). Outros ramos da física, como os estudos pneumáticos e do calor, assim como outras disciplinas, como a química e as ciências da vida, ficam de fora da Revolução Científica, tal como concebida por Koyré, porque não eram matematizáveis. A possibilidade de se matematizar o mundo é a característica principal da nova ciência, e, ao comentar a obra de Galileu, Koyré (1966, p. 227) afirma que a "boa física é feita a priori" ${ }^{144}$. Nesse sentido, o uso de experimentos e o método experimental não são características essenciais da ciência; seu emprego depende de uma nova concepção do universo: se a experimentação pressupõe uma linguagem em que os experimentos possam ser projetados e interpretados, e se a linguagem utilizada pela ciência é a matemática, é necessário que haja um processo de matematização do mundo anterior à realização de experimentos (ibid., p. 13). É por isso que Koyré considera nulo o papel de Francis Bacon na Revolução Científica: a nova ciên-

$142 \quad$ No original: "La forme géométrique est homogène à la matière: voilà pourquoi les lois géométriques ont une valeur réelle, et dominent la physique". Tradução minha.

143 No original: "All the disagreement between ancient and modern physics may be reduced to this: whereas for Aristotle, motion is necessarily an action, or more precisely an actualization, [...] it became for Galileo as for Descartes a state". Tradução minha.

144 No original: "La bonne physique se fait a priori”. Tradução minha. 
cia não se baseia no método experimental e numa nova lógica da pesquisa científica.

A Revolução Científica que vai de Copérnico até Newton - um período de cerca de cento e quarenta anos (KOYRÉ, 1957, p. ix) -, consiste numa mudança da estrutura metafísica do pensamento humano, da concepção de seu lugar no universo e de quais são os constituintes da realidade. Copérnico é ao mesmo tempo um conservador e um revolucionário: ao se manter fiel ao princípio platônico da circularidade do movimento dos astros, continua ligado à tradição grega; mas, ao propor seu modelo heliocêntrico como real, e não apenas como um instrumento de cálculo, Copérnico inicia o processo de matematização do universo, em que o real deve se conformar à geometria, e que irá gerar a ciência clássica ${ }^{145}$ (KOYRÉ, 1973, p. 15-17). Se a chave interpretativa proposta por Koyré é aceita, ao historiador da Revolução Científica cabe traçar o desenvolvimento das concepções de mundo, desde um cosmos fechado e hierárquico até o universo infinito e homogêneo de Newton ${ }^{146}$. A resolução dos problemas básicos do movimento exigia uma profunda mudança metafísica, que acaba por mudar a própria concepção do homem sobre seu lugar no universo; a nova física era "ao mesmo tempo a expressão e o fruto" ${ }^{147}$ da mudança intelectual ocorrida (KOYRÉ, 1966, p. 12).

A explicação da ocorrência da Revolução Científica na Europa do século XVII dada por Koyré é diferente daquela de Zilsel. Segundo Koyré, o mecanicismo da nova ciência nasceu na Europa do século XVII, e não na Grécia antiga, porque os gregos não admitiam que a precisão fosse possível no mundo sublunar, mas apenas no movimento constante e regular dos astros nos céus: era possível, assim, uma astronomia matemática, mas não uma física matemática (KOYRÉ, 1986, p. 62). A precisão matemática não havia sido, até a Revolução Científica,

$145 \quad$ Koyré prefere chamar a ciência da Revolução Científica do século XVII de "clássica", e não "moderna", adjetivo que guarda para a física quântica (KOYRÉ, 1966, p. 12).

146 É o que, de fato, faz Koyré em From the Closed World to the Infinite Universe (KOYRÉ, 1957).

147 No original: "à la fois l'expression et le fruit". Tradução minha. 
uma necessidade nos assuntos terrestres: "nunca ninguém procurou ultrapassar o uso prático do número, do peso, da medida, na imprecisão da vida quotidiana [...] para fazer dele um elemento do saber exato" (ibid., p. 71).

É por isso que Koyré não pode aceitar a tese de Zilsel: enquanto para o último a ciência moderna nasce a partir da aceitação e do uso, por parte dos intelectuais, do método experimental utilizado pelos artistas, artesãos e engenheiros, para o primeiro a gênese da nova ciência se dá por uma mudança daquilo que podemos caracterizar como "uma mentalidade"148 (COHEN, 1994, p. 86). Koyré reconhece que

[...] os artistas, engenheiros, arquitetos, etc., do Renascimento tiveram um papel importante na luta contra a tradição aristotélica e que alguns deles - como Leonardo da Vinci e Benedetti - procuraram mesmo desenvolver uma dinâmica nova, antiaristotélica; todavia, esta dinâmica [...] era [...] a dinâmica do impetus (KOYRÉ, 1986, p. 13).

Entretanto, a nova ciência não nasce da confluência do método experimental com a matemática - ainda que Koyré (1966, p. 16) reconheça a importância e o caráter inovador da experimentação, distinta da experiência - mas da nova concepção do mundo, de uma nova metafísica que cria as próprias condições para a valorização do método experimental, e essa mudança se manifesta no trabalho teórico do cientista: "ciência é essencialmente teoria, e não coleta de fatos" (KOYRÉ, 1986, p. 14). O terreno do artesão e do engenheiro renascentista é aquele do "mundo do mais ou menos", da impossibilidade de uma ciência exata do mundo físico; com a nova ciência, passa-se ao "universo da precisão".

A ciência de Koyré é basicamente teoria, que é criada a priori na estrutura de uma realidade matematizada. Koyré (2003, p. 36) chama sua posição de "realismo matemático"149, e afirma que no longo prazo apenas ela se revela produtiva para a ciência, ao contrário do empirismo e do pragmatismo convencionalista. Ao mostrar o papel da metafísica na produ-

\footnotetext{
148 No original: "a mentality". Tradução minha.

149 No original: "realismo matematico". Tradução minha.
} 
ção de teorias científicas, Koyré se afasta dos positivistas lógicos que afirmam que proposições não verificáveis empiricamente não possuem significado. De fato, as obras de Koyré foram um duro golpe contra o Positivismo Lógico (HODGE; CANTOR, 1990, p. 847), ao enfatizar o papel de atitudes filosóficas, não verificáveis, em relação ao mundo na criação da ciência.

A ênfase de Koyré nas mutações intelectuais e no papel da metafísica ao criar um mundo matematizado propício para a ciência deixa de fora, porém, alguns aspectos da Revolução Científica. Ainda que Koyré não considerasse supérfluo o estudo de outros pontos dessa Revolução, os fundamentos dela eram sempre as mudanças intelectuais, e não quaisquer mudanças sociais, ou mesmo metodológicas (como no caso da ênfase baconiana no método experimental), que porventura a acompanhassem. Esse aspecto da historiografia de Koyré foi criticado por, entre outros, A. Rupert Hall. Para Hall (1987, p. 490), a "Revolução Científica [...] é mais larga e mais difusa do que o desenvolvimento da mecânica clássica de Galileu a Newton"150 e se apoia em três pontos: matemática, metafísica e conhecimento empírico. Hall considera que Koyré tratou adequadamente os dois primeiros pontos, mas desprezou injustamente o último (ibid., p. 492). Isso porque, ao manter a ideia básica de Koyré, de que a Revolução Científica é uma mudança intelectual, pode-se mostrar que o novo valor dado à experimentação é também uma mudança conceitual e metafísica. Essa é a tarefa que Paolo Rossi tomou para si, ao mostrar como a valorização do método dos artesãos e engenheiros, longe de ser um aspecto secundário da Revolução Científica, leva a uma mudança intelectual do mesmo status que aquela enfatizada por Koyré. Nesse sentido, creio que podemos dizer que a obra de Rossi, principalmente seu livro I filosofi e le macchine, é uma união das ideias de Zilsel e de Koyré, no sentido de que combina a tese do primeiro com uma investigação sobre uma mudança intelectual, típica da historiografia do segundo.

\footnotetext{
$150 \quad$ No original: "The scientific revolution [...] is larger and more diffuse than the development of classical mechanics from Galileo to Newton". Tradução minha.
} 


\section{Rossi: filosofia e máquinas}

Em seu I filosofi e le macchine ${ }^{151}$, de 1962, Paolo Rossi leva adiante a tese de Zilsel acerca das condições do nascimento da ciência moderna, mas evita alguns de seus pontos problemáticos. Em primeiro lugar, Rossi não pretende fazer uma análise comparativa da ciência europeia com outras ciências, como a grega antiga ou a chinesa. Com a vantagem de explorar um campo já aberto, o livro de Rossi foca-se especificamente na Europa e estuda as condições de surgimento da ciência moderna naquele continente e naquela época, sem pretensão de gerar uma lei geral que permita a análise das razões pelas quais a Revolução Científica não ocorreu em outro lugar ou tempo. Em segundo lugar, Rossi evita uma certa indeterminação das ideias de Zilsel, ao mostrar exatamente como o tema da valorização das técnicas, através de suas aparições e desenvolvimentos em vários autores, acaba por influenciar o pensamento de Francis Bacon e mudar o próprio conceito de ciência. Essa escolha por Bacon não é gratuita: ainda que Rossi negue ao Lorde Chanceler o título de "pai da ciência moderna"152 (ROSSI, 2009, p. 127), dá a ele as honras por ter sido o primeiro a expressar filosófica e sistematicamente as novas concepções que pairavam no horizonte cultural.

Rossi aponta que novos modos de entender o mundo, típicos de uma mudança conceitual tal como aquela estudada por Koyré, aparecem em outras áreas que não apenas aquelas ligadas à física e à astronomia, ou à matematização da natureza: ideias de um saber como construção, o modelo da máquina como explicação do mundo físico, a visão de Deus como relojoeiro, e de que o homem só pode conhecer verdadeiramente aquilo que faz ou constrói são estreitamente ligadas à penetração do modo de ver dos técnicos e artesãos no mundo dos intelectuais (ROSSI, 2009, p. 23).

$151 \quad$ É interessante notar que o título do livro de Rossi é quase o mesmo de um artigo de Koyré, publicado em 1948 e depois inserido na coletânea Études d'histoire de la pensée philosophique (1961), chamado Les philosophes et la machine.

152 No original: "padre della scienza moderna". Tradução minha. 
Uma das marcas desse novo clima intelectual é a concepção de progresso, advinda dos tratados técnicos e dos livros de máquinas [libri di macchine] renascentistas, em direção a um saber sempre mais universalizado, passível de ser corrigido e ampliado por novas gerações, e que possa melhorar as condições humanas - isto é, distanciado do ideal antigo de pura contemplação (ROSSI, 2009, p. 21). Esse novo saber é caracterizado pela ideia de que a ciência é uma construção lenta, jamais terminada, com a qual todos podem contribuir; de que ela necessita de colaboração para o seu progresso, e, para isso, da criação de novos institutos sociais e linguísticos, tanto para sua produção quanto sua difusão; de que a pesquisa científica tem como fim a vantagem não de um indivíduo ou grupo, mas de todo o gênero humano; e de que o progresso da ciência é mais importante do que os as ambições ou os destinos individuais daqueles que a fazem progredir (ibid., p. 79).

Se um dos problemas da obra de Zilsel era o fato de não explicar qual era a justificação filosófica para a adoção do método experimental por parte dos intelectuais - por adotar um tipo de explicação mais sociológica -, um dos méritos de Rossi é justamente preencher essa lacuna, e isso através da análise do pensamento de um filósofo desprezado por Koyré: Francis Bacon. O que faz Rossi é mostrar como, dentro da filosofia de Bacon, o ideal de progresso indica uma mudança mais profunda, que ocorre na própria concepção de natureza e de verdade, ou seja, uma mudança metafísica nos moldes privilegiados por Koyré.

Rossi considera que a primeira expressão filosófica da nova concepção da ciência aparece com Francis Bacon. Segundo Rossi, Bacon percebe as profundas alterações que se estão operando em seu tempo e lança um programa de mudança cultural que possa acomodar as novas ideias (ROSSI, 2009, p. 94). Isso significa mostrar a infertilidade da filosofia que está na base da ciência aristotélica que Bacon critica. A infertilidade da filosofia, segundo Bacon, mostra-se na incapacidade de resolver os velhos problemas que se acumulam desde os gregos antigos. Para ele, isso acontece porque nas ciências intelectuais o conhecimento é gerado por apenas um indivíduo. Em contra- 
posição ao modo como a filosofia e as artes liberais avançam no tempo, Bacon propõe o modelo das artes mecânicas: devido à colaboração de muitos, essas artes sempre progridem - progresso e colaboração são tão importantes que devem ser considerados como as próprias marcas que separam a ciência de outros tipos de saber (ibid., p. 97).

Bacon considera que o conhecimento dos antigos dependia dos meios à sua disposição. O grande problema, que é ao mesmo tempo a razão da necessidade de uma reforma de toda a cultura, é que os antigos transformaram a sua insuficiência técnica em ontologia (ROSSI 2009, p. 98). A ideia de um conhecimento desinteressado e as afirmações sobre as impossibilidades naturais deveram-se ao fato de que os antigos não foram capazes de criar os meios técnicos suficientes e adequados para fazer com que a natureza revelasse seus segredos.

Se os antigos e medievais, ainda que utilizassem a experiência, não faziam experimentos, assim era porque consideravam que a natureza era formada por entes que possuíam tendências naturais a agir de certo modo, e não de outro; sendo assim, realizar um experimento seria o mesmo que atrapalhar a tendência natural das coisas, e de pouco ou nenhum uso para se obter conhecimento (GRANT, 1996, p. 159). Com a nova valoração das técnicas, e explicitamente em Bacon, as novas formas de se obter determinados efeitos naturais passaram a ser vistas não mais como modos de "enganar" a natureza, mas como modos de se observar a natureza em movimento. Ampliase assim a noção de natureza, ao mesmo tempo em que se liga o conhecimento do mundo natural à sua dominação - torna-se possível o surgimento de uma tradição experimental.

Bacon opera uma transformação também no conceito de verdade, negando que o conhecimento contemplativo preconizado pelos autores antigos seja superior ao saber prático. Para Bacon, ao contrário, verdade e utilidade são a mesma coisa (ROSSI 2009, p. 160). Isso significa que o próprio modo de agir sobre a realidade é que estabelece quais são as ações possíveis sobre ela, e a partir daí, quais são as suas características essenciais - o real não é dado a priori, com categorias e entidades 
fixas, mas são as operações humanas que o definem e o redefinem. O reconhecimento da historicidade do saber leva, assim, à ideia de que o conhecimento e a verdade são dependentes dos meios técnicos de ação sobre o real: a partir de agora, conhecer a natureza significa agir sobre ela (ibid., p. 176).

Ao adotar a posição de Zilsel sobre o papel da união dos métodos dos artesãos com os dos intelectuais na Revolução Científica, Rossi procura mostrar os determinantes sociais da ciência moderna; ao adotar o tipo de análise conceitual utilizado por Koyré para explicar como Bacon chega a uma nova ideia de natureza e de verdade, Rossi mostra outro tipo de "mutação intelectual" além da matematização da natureza. Sua intenção não é simplesmente unir as duas abordagens, de Zilsel, mais sociológica, e de Koyré, mais conceitual ${ }^{153}$, mas "tomar distância das simplificações que estão presentes nessas alternativas"154 (ROSSI, 2006, p. xiii).

\section{Considerações finais}

Zilsel, Koyré e Rossi possuem formação filosófica e são autores famosos no campo da história da ciência. Se suas obras possuem divergências entre si em pontos tanto historiográficos quanto filosóficos, como o tipo de explicação histórica adequada e a natureza da ciência, há também nelas concordância acerca da ocorrência de uma Revolução Científica, de que os resultados dessa Revolução levam até a ciência atual, e de que é possível dar uma explicação global desse evento. O diálogo de ideias dos três autores deixa claro que a história da ciência por eles praticada implica concepções filosóficas sobre a ciência (PÉCHEUX; FICHANT, 1989, p. 113): enquanto historiadores, suas obras revelam diferentes visões sobre a ciência passado,

153 Por razões a serem abordadas em outra ocasião, não acredito que se possa dizer, sem maiores considerações, que o tipo de historiografia escrito por Zilsel é externalista, e aquele de Koyré, internalista. Concordo com Beltrán que "externalismo" e "internalismo" são conceitos relativos, e termos valorativos utilizados pelos historiadores na apreciação ou depreciação do trabalho próprio ou alheio (BELTRÁN 1995, p. 183).

$154 \quad$ No original: "presa di distanza dalle semplificazioni che sono presenti in quelle alternative". Tradução minha. 
baseadas em diferentes filosofias; enquanto filósofos, suas versões acerca da Revolução Científica implicam um estudo cerrado dos conteúdos da ciência e das fontes do período.

Ao se referir ao seu I filosofi e le macchine, Rossi afirma que não se trata de um trabalho que não pertence "nem ao gênero 'história da filosofia', nem àquele 'história da ciência"'155 (ROSSI, 2009, p. 15) - acredito que essa caracterização, ao abolir a fronteira rígida entre história e filosofia, possa ser ampliada aos dois outros autores aqui tratados e, mais, indicar um modelo possível de interação frutífera entre as disciplinas numa prática de pesquisa em que história e filosofia da ciência estão, para além dos discursos metodológicos, juntas.

\section{Referências}

AGASSI, J. Science and its history: A reassessment of the historiography of science. Dordrecht: Springer, 2008.

BELTRÁN, A. Revolución Científica, Renacimiento e historia de la ciencia. Madri: Siglo Veintiuno de España, 1995.

BUNGE, M. Two unification strategies: Analysis or reduction, and synthesis or integration. In: SYMONS, J.; POMBO, O; TORRES, J. M. (Orgs.). Otto Neurath and the unity of science. Dordrecht: Springer, 2011, p. 145-157.

CANEVA. K. L. What in truth divides historians and philosophers of science?. In: MAUSKOPF, S.; SCHMALTZ, T. (Orgs.). Integrating history and philosophy of science: Problems and prospects. Dordrecht: Springer, 2012, p. 49-57.

COHEN, H. F. The Scientific Revolution: A historiographical inquiry. Chicago: University of Chicago Press, 1994.

FREUDENTHAL, G.; MCLAUGHLIN, p. (Orgs.). The social and economic roots of the Scientific Revolution: Texts by Boris Hessen and Henryk Grossmann. Dordrecht: Springer, 2009.

GAVROGLU, K. O passado das ciências como história. Tradução Custódio Magueijo. Porto: Porto Editora, 2007 [2004].

GIERE, R. N. History and philosophy of science: Intimate relationship or marriage of convenience?. British journal for the philosophy of science, Londres, n. 24, p. 282-297, 1973.

$155 \quad$ No original: “né al genere 'storia della filosofia', né a quello 'storia della scienza”. Tradução minha. 
GILLISPIE, C. Koyré, Alexandre. In: GILLISPIE, C. (Org.). Dictionary of scientific biography. Nova Iorque: Simon \& Schuster Macmillan, 1981. v. 7, p. 482-490.

GRANT, E. The foundations of modern science in the Middle Ages. Cambridge: Cambridge University Press, 1996.

HALL, A. R. Alexandre Koyré and the Scientific Revolution. History and Technology, Londres, v. 4, p. 485-495, 1987.

HANSON, N. R. The irrelevance of history of science to philosophy of science. The Journal of Philosophy, Nova Iorque, v. 59, n. 21, p. 574-586, 1962.

HODGE, M.; CANTOR, G. The development of philosophy of science since 1900. In: OLBY, R. et al. (Orgs.). Companion to the history of modern science. Londres: Routledge, 1990, p. 838-852.

KOYRÉ, A. From the closed world to the infinite universe. Baltimore: Johns Hopkins Press, 1957.

KOYRÉ, A. Études d'histoire de la pensée philosophique. Paris: Colin, 1961.

KOYRÉ, A. Études galiléennes. Paris: Hermann, 1966 [1939-1940].

KOYRÉ, A. The Astronomical Revolution: Copernicus-Kepler-Borelli. Tradução R. E. W. Maddison. Londres: Methuen, 1973 [1961].

KOYRÉ, A. Galileu e Platão \& Do mundo do "mais ou menos" ao universo da precisão. Tradução J. T. Santos. Lisboa: Gradiva, 1986 [1943 e 1948].

KOYRÉ, A. Sull'influenza della filosofia sull'evoluzione delle teorie scientifiche. In: CAVAZZINI, A (Org.). Alexandre Koyré: Filosofia e storia. Milão: Mimesis, 2003 [1955], p. 25-38 .

KROHN, W.; RAVEN, D. The "Zilsel Thesis" in the context of Edgar Zilsel's Research Programme. Social Studies of Science, Londres, v. 30, n. 6, p. 925-933, 2000.

LAUDAN, L. et al. Scientific change: Philosophical models and historical research. Synthese, Dordrecht, v. 69, n. 2, p. 141-223, 1986.

LINDBERG, D. Conceptions of the Scientific Revolution from Bacon to Butterfield: A preliminary sketch. In: LINDBERG, D.; WESTMAN, R. Reappraisals of the Scientific Revolution. Cambridge: Cambridge University Press, 1990, p. 1-26.

MAUSKOPF, S.; SCHMALTZ, T. (Orgs.). Integrating history and philosophy of science: Problems and prospects. Dordrecht: Springer, 2012

NAGEL, E. The Structure of science: Problems in the logic of scientific explanation. Indianapolis: Hackett Publishing Company, 1979.

NEMETH, E. Logical Empiricism and the history and sociology of science. In: RICHARDSON, A.; UEBEL, T. (Orgs.). The Cambridge 
companion to Logical Empiricism. Cambridge: Cambridge University Press, 2007, p. 278-302.

PAPINEAU, D. Science, problems of the philosophy of. In: HONDERICH, T. (Org.). The Oxford Companion to Philosophy. 3. ed. Oxford: Oxford University Press: 2005.

PÉCHEUX, M.; FICHANT, M. Sobre a história das ciências. Tradução F. Bairrão. Lisboa: Editorial Presença; São Paulo: Edições Mandacaru, 1989 [1969].

ROSSI, p. Storia e filosofia: Saggi sulla storiografia filosofica. 2. ed. Torino: Einaudi, 1975.

ROSSI, p. Premessa. In: ROSSI, p. (Org.). Storia della scienza: 1. La Rivoluzione Scientifica dal Rinascimento a Newton. Novara: Instituto Geografico De Agostini, 2006, p. xi-xix.

ROSSI, p. I filosofi e le macchine: 1400-1700. 3. ed. Milão: Feltrinelli, 2009.

SHAPIN, S. Zilsel-Thesis. In: BYNUM, W. F. et al. (Orgs.). Dictionary of the history of science. Londres: Macmillan, 1981, p. 450.

ZILSEL, E. The social origins of modern science. Organização D. Raven, W. Krohn e R. Cohen. Dordrecht: Springer, 2003. 